\title{
Monitoring of the Environmental Corrosivity in Museums by RFID Sensors: Application to Pollution Emitted by Archeological Woods
}

\author{
Stephane Rioual ${ }^{1, *(\mathbb{D})}$, Benoit Lescop ${ }^{1}$, Julien Pellé ${ }^{1}$, Gerusa De Alkmim Radicchi ${ }^{2}$, Gilles Chaumat ${ }^{2}$, Marie \\ Dominique Bruni ${ }^{2}$, Johan Becker ${ }^{3}$ and Dominique Thierry ${ }^{3}$ \\ 1 Lab-STICC, University Brest, CNRS, UMR 6285, F-29200 Brest, France; benoit.lescop@univ-brest.fr (B.L.); \\ Julien.Pelle@univ-brest.fr (J.P.) \\ 2 ARC-Nucléart, 38054 Grenoble, France; Gerusa.DEALKMIMRADICCHI@cea.fr (G.D.A.R.); \\ gilles.chaumat@cea.fr (G.C.); Marie-dominique.bruni@cea.fr (M.D.B.) \\ 3 Institut de la Corrosion, 29200 Brest, France; johan.becker@institut-corrosion.fr (J.B.); \\ dominique.thierry@institut-corrosion.fr (D.T.) \\ * Correspondence: rioual@univ-brest.fr
}

check for updates

Citation: Rioual, S.; Lescop, B.; Pellé, J.; Radicchi, G.D.A.; Chaumat, G.; Bruni, M.D.; Becker, J.; Thierry, D. Monitoring of the Environmental Corrosivity in Museums by RFID Sensors: Application to Pollution Emitted by Archeological Woods. Sustainability 2021, 13, 6158. https:// doi.org/10.3390/su13116158

Academic Editor: Asterios Bakolas

Received: 6 May 2021

Accepted: 28 May 2021

Published: 30 May 2021

Publisher's Note: MDPI stays neutral with regard to jurisdictional claims in published maps and institutional affiliations.

Copyright: (c) 2021 by the authors. Licensee MDPI, Basel, Switzerland. This article is an open access article distributed under the terms and conditions of the Creative Commons Attribution (CC BY) license (https:/ / creativecommons.org/licenses/by/ $4.0 /)$.

\begin{abstract}
The control of air quality in museums or storages is of fundamental interest for the conservation of historic artifacts. The present work reports an example of application of RFID sensors developed in the European project SensMat and dedicated to this issue. The sensors are based on the variation of property of an RFID tag coupled with a sensitive silver thin film exposed to the environment. As it will be described in the paper, such low-cost sensors are interrogated by a commercial reader and provide the environmental corrosivity index and thus the presence of pollutants. The selected case study concerns the monitoring of pollution by $\mathrm{H}_{2} \mathrm{~S}$ in a building dedicated to conservation and restoration of archeological and historical woods. The ability of sensors to map spatially the corrosivity within buildings is highlighted.
\end{abstract}

Keywords: environmental corrosivity; air quality; IOT; autonomous sensor; RFID; corrosion; archeological wood

\section{Introduction}

Air pollution monitoring is of crucial interest for conservation and protection of historical artifacts in indoor environments. Indeed, gaseous pollutants in air are responsible of the degradation of many types of objects and materials. They are of diverse nature (organic acids, $\mathrm{H}_{2} \mathrm{~S}, \mathrm{NH}_{3}, \mathrm{SO}_{2}, \mathrm{NO}_{2}$, etc.) and are produced either internally in the building where are localized artifacts or externally due to outdoor pollution [1]. Some devices dedicated to the monitoring of air quality exist and may be applied for cultural heritage conservation. These include the use of sampling techniques or gas sensors. An alternative to these methods is to consider the chemical reactivity of metallic surfaces. In this case, all synergic parameters including the pollutants, temperature and humidity are taken into account. The measurement of the quantity of corrosion products at the surface as well as the mass loss of metal is then an indicator environmental corrosivity and allows evaluating the risk to the objects' integrity. For indoor applications, the ISO 11844-1 standard [2] gives the IC corrosivity classes which range from IC1 (very low corrosivity) to IC5 (very high corrosivity). Steel, zinc, copper and silver are sensitive to different pollutants and are therefore selected in this standard.

Electrical resistance (ER) is a well-established method to provide the IC class. In particular, the AirCorr ${ }^{\mathrm{TM}}$ sensor was commercialized within a project supported by the European Commission (Protection of cultural heritage by real-time corrosion monitoring) and dedicated to the monitoring of corrosive atmospheres in the cultural heritage sector [3-5]. In this case, the sensitive part the sensor is constituted by a strip elaborated 
in copper or silver. From the change in geometry of this metallic element (i.e., thinning) induced by corrosion, it is possible to calculate the loss of metal thickness and hence the corrosivity class IC.

During the last decades, Radio-Frequency Identification (RFID) technology has become more and more popular in many industries and for a variety of applications includng the cultural heritage sector [6,7]. It is indeed an efficient way to transfer data and track items. This attractiveness is explained by the ability of this technology to interrogate numerous tags at a very low price and with a low visual nuisance. Recently, RFID sensors were proposed for corrosion monitoring [8-19]. Within the European project SensMat, an UHF-RFID corrosion sensor was in particular developed to assess air quality and IC classes in museums [19]. It was subsequently applied for civil engineering applications [20]. As for ER sensors, the change of electrical resistance of a thin metallic film induced by corrosion is used to provide information on the environmental corrosivity. Due to its very low cost, this type of sensor is affordable for all museums including small ones and can be deployed at large scale.

The present study aims at demonstrating the interest of such sensors for monitoring the presence of air pollutants in buildings dedicated to cultural heritage such as museums, storages, etc. This was performed at the ARC-Nucleart institute, which is specialized in conservation-restoration of archeological and historical woods. Archeological woods undergo a conservation treatment in the workshop by conventional chemical treatments based on polyethylene glycol (PEG). However, for large structures such as ships, this process does not exclude the formation of acidic iron species at the surface [21,22]. These latter are known to generate $\mathrm{H}_{2} \mathrm{~S}$ pollution in the atmosphere and may affect other historical objects present in the building such as metals or pigments. Within this context, monitoring corrosivity of several areas in the building is of crucial interest. The present work describes first the buildings under monitoring and in more details the selected areas. The principle of RFID sensors which are based on the chemical reactivity of silver thin films is then presented. The results achieved by the sensors highlight clearly that the degree of pollution by $\mathrm{H}_{2} \mathrm{~S}$ is restricted to some area. In particular, due to the HVAC equipment, the laboratory used for restoration of polychromatic woods presents a low or very low corrosivity index with respect to storage rooms where acidification of archeological woods is an issue for conservation. These results are supported by data obtained by chemical analysis of sensitive thin films after exposure.

\section{Materials and Methods}

\subsection{Realisation of RFID Sensors and Samples Analysis}

Due to the strong reactivity of silver surfaces to sulphide, silver thin films were inserted in RFID sensors. They were deposited on polycarbonate substrates $\left(2.0 \times 8.5 \mathrm{~cm}^{2}\right)$ by radiofrequency magnetron sputtering (Univex 350, Oerlikon). For sputtering deposition, the working chamber was vacuumed to reach a base pressure of $3 \times 10^{-7} \mathrm{mbar}$. The substrate was fixed at a distance of ca. $8 \mathrm{~cm}$ parallel to the $\mathrm{Ag}$ target surface (diameter: 3 inches). Films were deposited for 30 seconds in Argon plasma. The Argon purity was 99.999\%. During deposition, the pressure was kept at $7 \times 10^{-3} \mathrm{mbar}$. The input power at the target was $100 \mathrm{~W}$. The resulting layers were ca. $20 \mathrm{~nm}$ thick. X-ray diffraction (XRD) was done to analyze the crystalline structure of the Ag layers using PANalytical Empyrean apparatus with CuK radiation $(1.5408 \AA$ ) .

\subsection{Description of Areas under Monitoring}

The influence of archeological wood on the air quality was studied in two buildings. The maps of the buildings are presented in Figure 1. The localizations of archeological materials containing pyrite $\left(\mathrm{FeS}_{2}\right)$ are indicated in the maps by blue stars. 


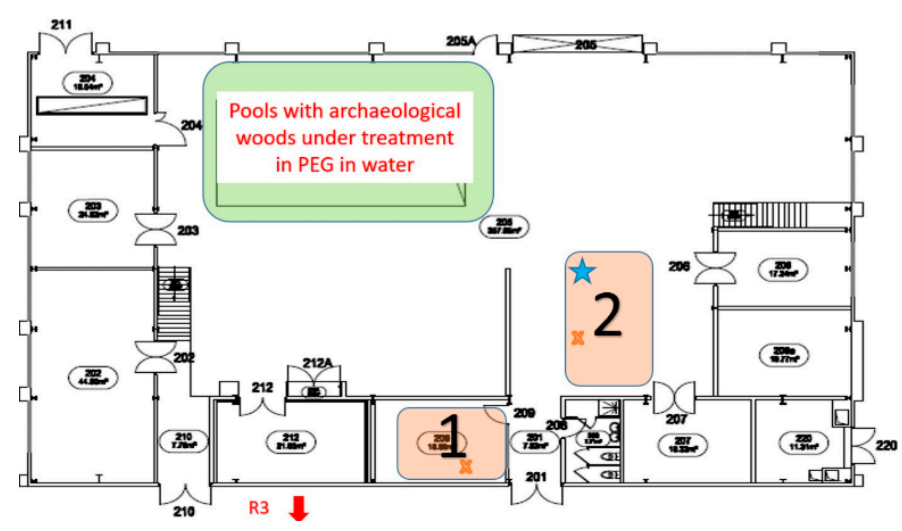

(a)

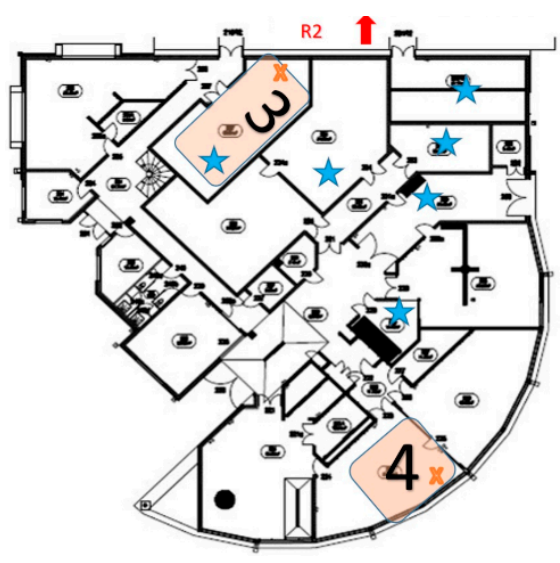

(b)

Figure 1. (a) Description of the first building; (b) Description of the second building. Locations of archeological wood are indicated by blue stars. The brown squares and the brown crosses indicated the room selected for the monitoring and the locations of sensors in these rooms.

Such archeological objects are considered to be the main source of pollution by $\mathrm{H}_{2} \mathrm{~S}$. Indeed, pyrite oxidizes naturally following the reaction [23-26]:

$$
\mathrm{FeS}_{2}+\mathrm{H}_{2} \mathrm{O}+\frac{7}{2} \mathrm{O}_{2} \rightarrow \mathrm{Fe}^{2+}+2 \mathrm{SO}_{4}^{2-}+2 \mathrm{H}^{+}
$$

After this step, the oxidation of Fe(II) can occurs to form Fe(III) which can then, a priori, oxidize $\mathrm{FeS}_{2}$ at a much higher rate than oxygen.

$$
\begin{gathered}
2 \mathrm{Fe}^{2+}+\frac{1}{2} \mathrm{O}_{2}+2 \mathrm{H}^{+} \rightarrow 2 \mathrm{Fe}^{3+}+\mathrm{H}_{2} \mathrm{O} \\
\mathrm{FeS}_{2}+14 \mathrm{Fe}^{3+}+8 \mathrm{H}_{2} \mathrm{O} \rightarrow 15 \mathrm{Fe}^{2+}+2 \mathrm{SO}_{4}^{2-}+16 \mathrm{H}^{+}
\end{gathered}
$$

The main consequence of this is the significant formation of protons which induce $\mathrm{H}_{2} \mathrm{~S}$ pollution by reaction of this extreme acidity on pyrite itself.

Due to the localization of objects containing pyrite in the buildings, some areas were selected for the monitoring of the pollution. As seen in Figure 1a, two monitored spaces are in the first building: the biochemistry laboratory (space 1) and the temporary storage area for archaeological artefacts (space 2). Two locations are also selected in the second building where most of the objects are stored: the storage area for archaeological artefacts (space 3) and the sculpture workshop (space 4). Archeological woods, i.e., the sources of $\mathrm{H}_{2} \mathrm{~S}$ pollution are present in storage areas (spaces 2 and 3 ) and not at the two others surrounding locations (spaces 1 and 4 ).

Figure 2 displays pictures of the monitored areas in the first building which is dedicated to the reception of archaeological artifacts and to their treatment by PEG. The entrance hall is shown in Figure 2a. In this large open space area, archeological wood treatment pools can be seen. A big shed displayed in Figure $2 b$ is also present and serves as temporary storage room for archaeological artefacts. Materials stored in this place are: wood, leather, vegetal fibers, and metals. The environmental corrosivity inside the shed was monitored due to the presence of potential sources of $\mathrm{H}_{2} \mathrm{~S}$ (space 2). Indeed, as seen in Figure 2c, a large plastic package containing a treated archeological basket with sediments and a treated boat placed on the metallic support are stored at this location. In the first building, to evaluate the air quality in other rooms, the biochemistry laboratory (space 1) was also selected. It is separated by only few meters from the shed. In this room, no archeological wood is stored. Figure 2d displays a picture of this area. 


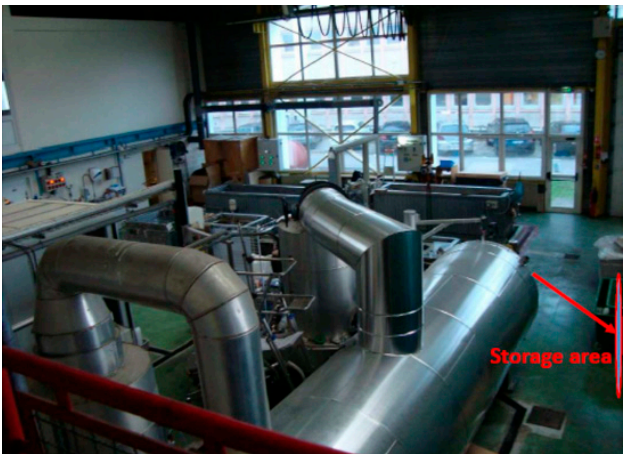

(a)

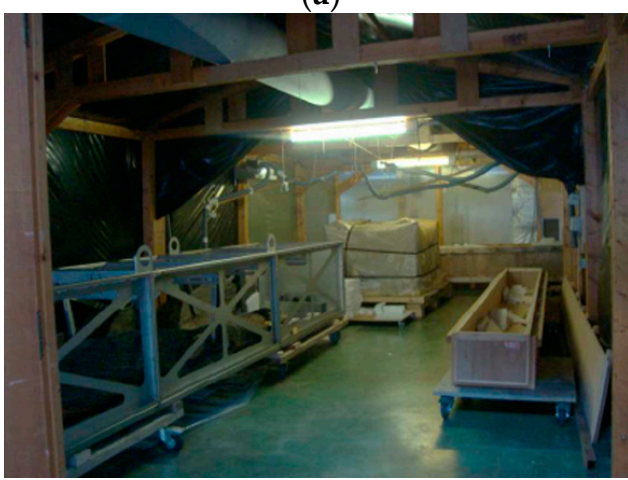

(c)

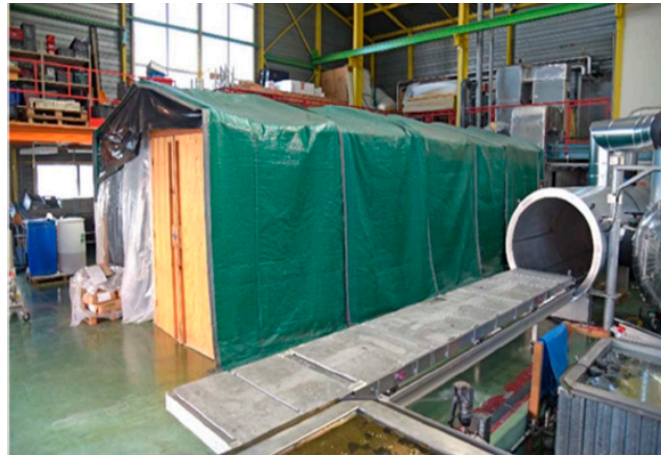

(b)

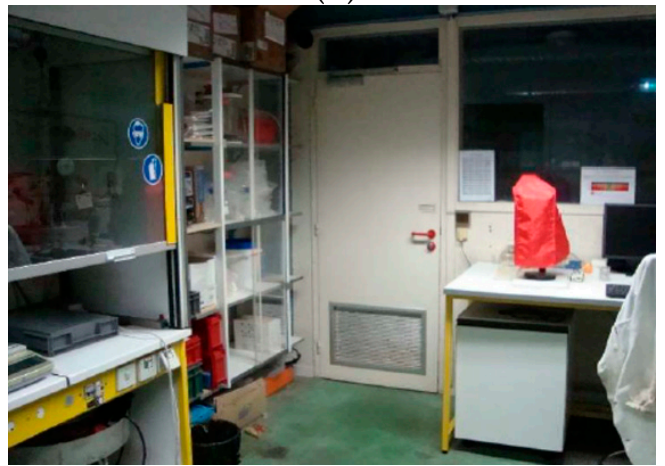

(d)

Figure 2. (a) Entrance hall for treatment of woods; (b,c) The shed used for temporary storage area (space 2); (d) The biochemistry laboratory (space 1).

Figure 3 display pictures of the spaces under monitoring in the second building. This latter concentrates the majority of restoration workshops and storage of archeological and historical collections. The archaeological storage area (space 3) is depicted in Figure 3a and stores wooden after their resin/drying treatment. Some integrated metal in very small proportion was also there. The wood comes from boats at different historical periods, from Romans to Modern. The HVAC keeps the temperature and relative humidity constant at $22{ }^{\circ} \mathrm{C}$ and $45 \% \mathrm{RH}$.

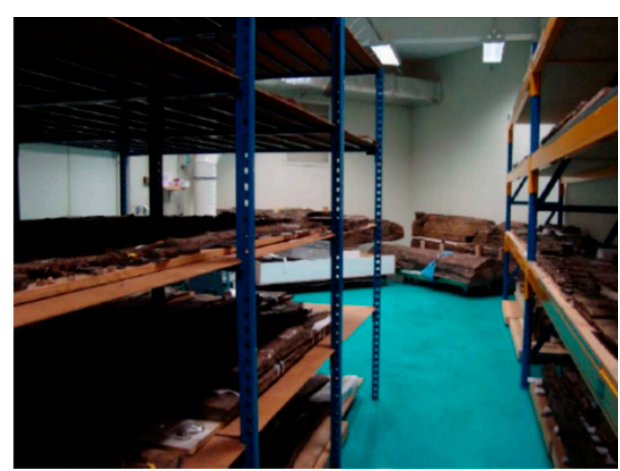

(a)

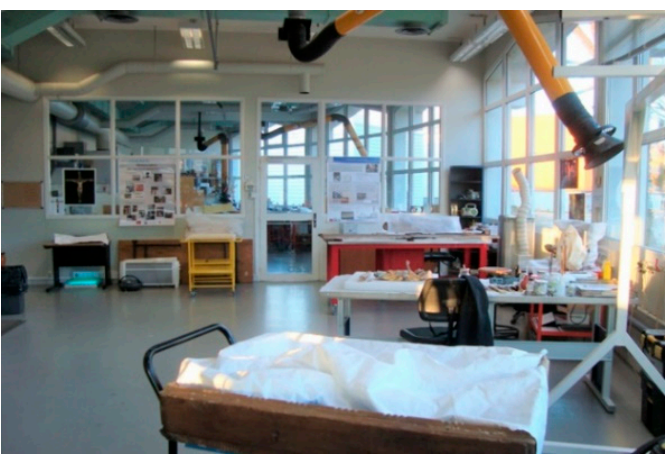

(b)

Figure 3. (a) Storage room for archeological woods (space 3); (b) Sculpture restoration workshops (space 4).

The sculpture restoration workshop (space 4) is shown in Figure 3b. In this area, activities of conservation-restoration for historical polychromatic wood are performed. Medieval, Renaissance and Early modern polychrome religious sculptures are the main objects restored in the Workshop. These polychromes are generally produced by metallic coatings (silver or gold) and colored pigments (metallic carbonates or acetates). Pollution 
by $\mathrm{H}_{2} \mathrm{~S}$ is a problem for such type of collection because this pollutant is known to react with metals even at very low concentrations leading to tarnishing surfaces and also with pigments, causing darkening of the polychromy [27-30]. To limit such effects, the HVAC of the room keeps the temperature and relative humidity relatively constant and below $25^{\circ} \mathrm{C}$ and $60 \%$ RH. Checking the low corrosivity in this space by the proposed method is a key point of the present study.

\section{Results and Discussion}

\subsection{Description of the Sensor}

The RFID sensor is presented in Figure 4a. Its dimensions are $11.3 \times 6.5 \mathrm{~cm}^{2}$. The principle of the sensor was described in details in Refs. $[19,20]$. It is based on the electromagnetic coupling between a metallic sensitive layer exposed to a corrosive environment and the antenna of an RFID tag. The sensitive layer is shown in Figure 4a. It is interacting with the RFID tag ALN-9654 "G" from Alien technologies which is localized under the white plastic film. Corrosion of this active layer induces an increase in its electrical resistance and hence, a change of the property of the coupled antenna. The signal strength emitted from the tag to the reader is then modified. This variation can be monitored by measuring the RSSI (Received Signal Strength Indication) by a commercial UHF-RFID reader. Due to this operating principle, the sensor in its initial state, i.e., before corrosion does not respond to the reader. This problem is solved by considering a second RFID tag which serves as a reference for the device. It is represented by dotted line in Figure 4a. Figure 4a displays the UHF-RFID reader used for the interrogation of the sensor. The portable CS108 model from Convergence Systems Limited was chosen. As shown, a mobile phone is connected by Bluetooth to the reader. The RSSI value and identification number associated with the two tags appears then on the mobile.

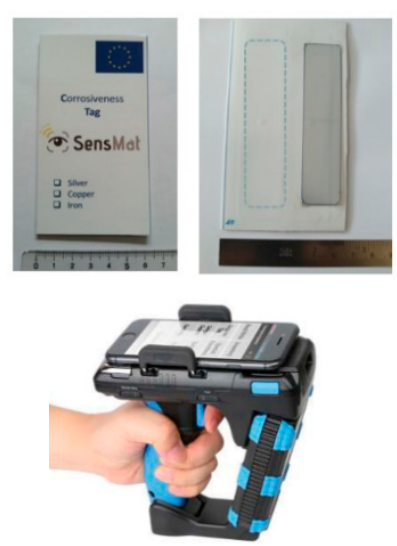

(a)

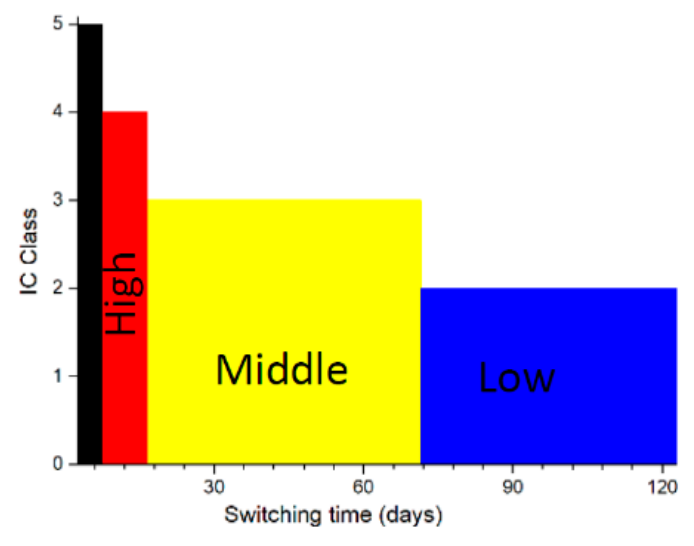

(b)

Figure 4. (a) The two sides of the sensor and the UHF-RFID reader; (b) The relation between the IC class and the detection time of the sensitive tag.

In the present work, silver thin films are used since this metal is known to be sensitive to $\mathrm{H}_{2} \mathrm{~S}$ [31]. To present the method and provide a calibration procedure, sensors produced by silver thin films of different thicknesses are considered. Table 1 reports the data for the interrogation of the sensors by maintaining a distance of $40 \mathrm{~cm}$ between the reader and the sensor. 
Table 1. RSSI values for the reference and sensitive RFID tags for several values of the silver thickness films. The electrical resistance of the thin films are also given.

\begin{tabular}{cccc}
\hline Thickness $(\mathbf{n m})$ & $\begin{array}{c}\text { RSSIReference } \\
\mathbf{( d B m})\end{array}$ & $\begin{array}{c}\text { RSSISensitive } \\
(\mathbf{d B m})\end{array}$ & $\begin{array}{c}\text { ElectricalResistance } \\
\mathbf{( \Omega )}\end{array}$ \\
\hline 20 & -45 & No detection & 14 \\
10 & -45 & No detection & 43 \\
7.5 & -45 & -55 & 82 \\
5 & -45.5 & -49 & 300 \\
\hline
\end{tabular}

As seen, the reference tag is interrogated with a RSSI value of $-45 \mathrm{dBm}$, independently of the thickness of the sensitive layer. The sensitive tag, it can be detected only when a metallic film of $7.5 \mathrm{~nm}$ thickness or less is present. For this thickness threshold value of $7.5 \mathrm{~nm}$, the difference between the two RSSI values is about $10 \mathrm{~dB}$. Decreasing the thickness of silver to $5 \mathrm{~nm}$ reduces this difference to $4 \mathrm{dBm}$. As shown in the table, the observed behavior is explained by the increase in the electrical resistance of the sensitive film. This variation does not depend linearly on the thickness, a result in agreement with numerous studies made on thin films. Moreover, the value of the electrical resistivity also deviates from the electrical conductivity of bulk materials. These results can be applied to atmospheric corrosion monitoring since, by assuming a uniform process, corrosion leads to a regular loss of metal thickness and hence to an increase in the electrical resistance. The corrosivity classification of indoor atmospheres is defined by the ISO 11844-1 standard [1] and is based on mass loss measurements of metallic coupons after 1 year of exposure. As detailed above, the principle of the proposed RFID method is founded on electrical resistance variations and not on mass loss measurements. Moreover, the exposure time of sensors in museums is expected to be less than 1 year to provide data to conservators in a limited time scale. As the consequence, the determination of IC classes via the standard cannot directly be applied. Only the corrosion rate in $\mathrm{nm} /$ day measured by the proposed method can be compared to the threshold limits for silver IC classes given in $\mathrm{mg} / \mathrm{m}^{2} /$ year by the ISO 11844-1. The same method is used for ER sensors. The value of the corrosion rate in $\mathrm{nm} /$ day is obtained by measuring a variation of the electrical resistance during an exposure time. For ER sensors, this can be done continuously. For RFID sensors, the detection of the sensitive tag indicates that the thickness of the metallic film is lower than $7.5 \mathrm{~nm}$. By producing a thin film with an initial thickness of $20 \mathrm{~nm}$, the corrosion rate is then defined by a loss of $12.5 \mathrm{~nm}$ divided by the switching time, i.e., the exposure time needed to detect the sensitive tag. Figure $4 \mathrm{~b}$ displays the relation between this switching time and the different IC classes. As seen, taken into account the limitations discussed above, if the sensitive tag is observed before 15 days of exposure, the IC class would be IC 5 or IC4. An IC 3 class (middle corrosivity) is achieved if this transition occurs between 16 and 71 days of exposure.

\subsection{Corrosivity Classes at Different Locations}

The sensors were interrogated each week from 15 December 2020 to 15 March 2021. Figure 5 a reports the exposure time needed to recover the signal from the sensitive tag. As observed, important differences exist between the different areas under monitoring. Indeed, the loss of $12.5 \mathrm{~nm}$ of metal thickness was achieved in the biochemistry laboratory (space 1) in 36 days. This time increases for the two storages rooms (spaces 2 and 3) to 50 and 57 days. The observation of the sensitive tag was never realized for the culture restoration workshop (space 4). The time needed to detect the sensitive tag is directly associated with the environmental corrosivity. Results achieved for the space 2 and 3 are similar. In these two cases, the non-negligible corrosivity is explained by the presence of numerous archeological woods in these storage areas and therefore some emission of $\mathrm{H}_{2} \mathrm{~S}$. In contrast, a very limited corrosion effect is measured in space four where polychromatic woods are restored. The absence of corrosion is then certainly due to the use of HVAC in 
the building. The higher corrosion rate observed in space 1 is rather surprising. It is indeed the worst case while no source of pollution emission is expected in this area.

\begin{tabular}{|c|c|}
\hline Location & Detection time (days) \\
\hline Space 1 & 36 \\
\hline Space 2 & 57 \\
\hline Space 3 & 50 \\
\hline Space 4 & $>95$ \\
\hline
\end{tabular}

(a)

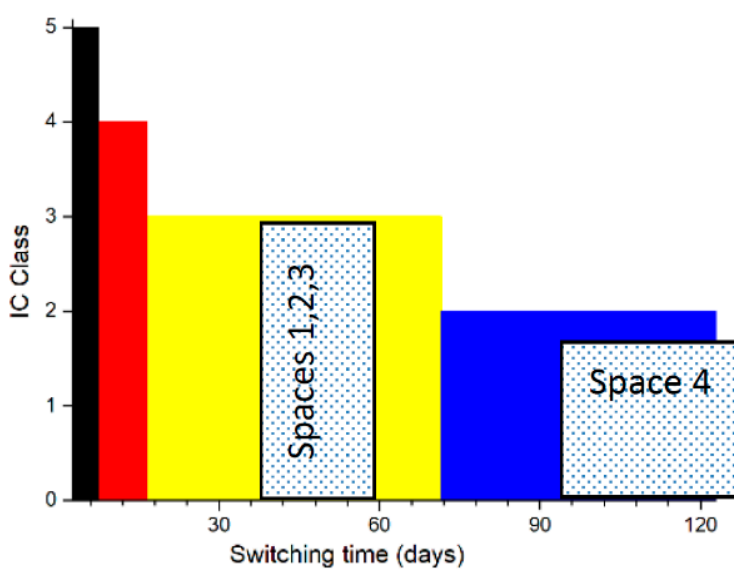

(b)

Figure 5. (a) Reporting of the detection time for the sensitive tag for the different areas under monitoring; (b) IC class for the different spaces.

As explained above, the IC index can be calculated from the time of detection. Figure $5 b$ present the index for the different locations. Middle corrosivity class (IC3) is measured for the space 1, 2 and 3. Space 4 presents a low corrosivity (IC2) or very low corrosivity (IC1) level.

\subsection{XRD Results}

To further get some insight on the results provided by sensors, the four sensitive metallic films were analyzed after their exposure by conventional analytical methods. Figure 6 displays the XRD patterns of the silver thin films.

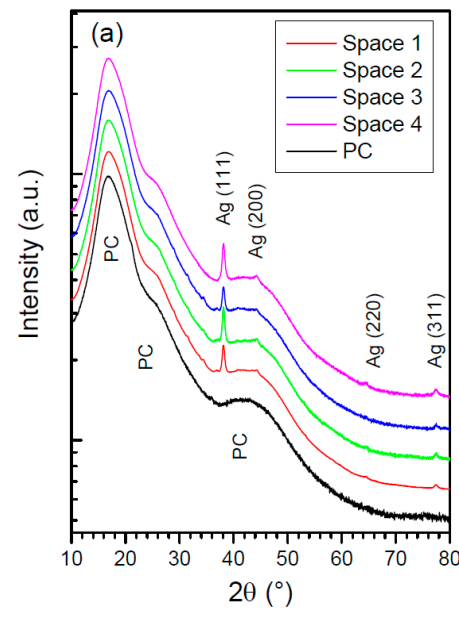

(a)

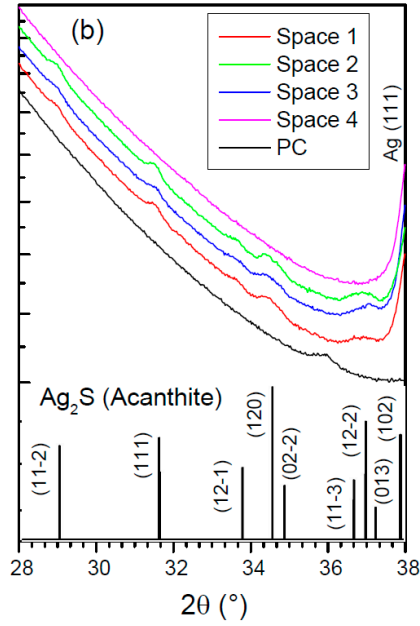

(b)

Figure 6. (a) XRD diffractograms of exposed silver samples and polycarbonate substrate; (b) XRD patterns between $28^{\circ}$ and $38^{\circ}$.

The characterization of the uncoated polycarbonate substrate is also presented as a reference. Figure 6 a shows the patterns in the range from $10^{\circ}$ to $80^{\circ}$. The broad structures observed at $17^{\circ}, 26^{\circ}$ and $42^{\circ}$ are attributed to the polycarbonate substrate. The peak corresponding to metallic silver $\mathrm{Ag}(111)$ appears at about $38^{\circ}$ for all sample. The highest 
intensity of this peak is obtained on the sample exposed in space 4, indicating that a higher metal thickness remains for this sample. This result is in agreement with the low IC index of this area measured by the sensor. To characterize more precisely the possible corrosion products, additional measurements were done from $28^{\circ}$ to $38^{\circ}$. They are presented in Figure $6 \mathrm{~b}$. Several peaks are clearly visible on samples exposed in spaces 1, 2 and 3 but not in space 4 . They are assigned to Acanthite $\mathrm{Ag}_{2} \mathrm{~S}$, which presents a monoclinic structure [32]. Studies focusing on reactivity of silver to $\mathrm{H}_{2} \mathrm{~S}$ are frequently reported in the literature [33-37]. The sulfidation process may occur via different pathways but leads always to the formation of $\mathrm{Ag}_{2} \mathrm{~S}$ on the surface, in agreement with our findings. Note that the presence of sulfur on the films after exposure was also checked by Energy-dispersive X-Ray Spectroscopy (EDS) for samples exposed in spaces 1, 2 and 3. From this result, it appears clearly that the high corrosivity of space 1 is also associated with sulfidation even if no source of emission is present in the room. The higher corrosion rate achieved in this area may be explained by the presence of sources in the vicinity (space 2 , for example) and by the presence of other contaminants in this area.

\subsection{Discussion}

The achieved results prove, via the presented case study, the interest of the proposed RFID sensor as an IOT tool for pollution monitoring in museums or storage areas. Fundamentally, the method is based on the variation of the electrical resistance of the sensitive thin film. So, it is very similar to that used by ER sensors. This was also shown in Ref [19] by comparing the response of these two types of sensors in laboratory environment. The advantage of the RFID sensors concerns its very low cost and low visual nuisance since no electronic is integrated inside the sensor. Moreover, the RFID readers can be used for other purpose in museums such as object tracking or getting information on artifacts for visitors. The drawback of the method with respect to ER sensors is the absence of measurement in real time and a lower sensitivity. However, as demonstrated in the present work, this not a critical point to evaluate in situ the IC index during few months of exposure and hence air pollution. It is noticeable that other methods exist for measurement of the IC index. They include the use of coupons and their subsequent analysis in laboratories after exposure, as well as continuous methods based on quartz balance measurements or ER sensors. A comparison between all these methods was performed by L. Hart et al. [38]. Significant differences were observed on corrosion rates extracted from these methods leading to the conclusion that valuable information on the variation of corrosion rates can be achieved only when a unique method is selected. These authors demonstrated also the strong influence of the orientation and position of sensors with respect to the air flux. In the present study, the positions of sensors are indicated by brown crosses in Figure 1. Their orientations are vertical except for the space 1, for which the sensors are horizontal. This difference may also be at the origin of the high corrosivity found in this particular area. The influence of air flux on the measured corrosivity rate further reinforces the interest of the proposed sensors. Indeed, the main interest of the RFID technology is the possibility to produce a large number of sensors at a reasonable cost. Multiplying the number of sensors should enable to get information about the role of air flux in corrosivity, especially in the case of rooms equipped with HVAC.

\section{Conclusions}

As a conclusion, the present work reports the application of corrosion RFID sensors produced with silver thin films for the monitoring of $\mathrm{H}_{2} \mathrm{~S}$ pollution in buildings dedicated to conservation and restoration of woods. The sensor can be considered as a binary sensor (True/False) based on the detection of a sensitive tag due to a loss of thickness induced by corrosion. From the detection of the threshold value, it is possible to define the index of environmental corrosivity of the monitored area and hence to provide a map of corrosivity of the buildings. The sensitivity of the sensor is a tunable parameter since it depends on the nature of the selected metal and on its initial thickness. Silver films with $20 \mathrm{~nm}$ 
thickness were chosen here to probe the IC3/IC2 categories with few months of exposure. The achieved results highlight the important role of HVAC to reduce the corrosivity level in the sculpture restoration workshop with respect to storage areas. The proposed method can be extended to many issues in museums or storage areas, and should, therefore, be considered as a promising one within the concept of preventive conservation for cultural heritage.

Author Contributions: Validation, S.R., B.L., J.P., G.C., G.D.A.R., M.D.B., J.B., D.T.; investigation, S.R., B.L., J.P., G.C., J.B.; visualization, S.R., G.D.A.R., writing-original draft preparation, S.R.; writing-review and editing, S.R., B.L., J.P., G.C., G.D.A.R., M.D.B., J.B., D.T.; project administration, S.R., G.C., M.D.B., D.T.; All authors have read and agreed to the published version of the manuscript.

Funding: This work received funding from the European Union's Horizon H2020 research and innovation program under grant agreement 814596 (Preventive solutions for Sensitive Materials of Cultural Heritage-SENSMAT). This work is also supported by the European Union through the European Regional Development Fund (ERDF), the Ministry of Higher Education and Research, the Région Bretagne, the Conseil général du Finistère and Brest Métropole Océane, through the CPER Project 2015-2020 MATECOM.

Institutional Review Board Statement: Not applicable.

Informed Consent Statement: Not applicable.

Conflicts of Interest: The authors declare no conflict of interest.

\section{References}

1. Fish, P.; Muller, C.; Thickett, D. An air quality standard for the protection of cultural heritage. Papyrus 2014, 15, 26-29.

2. ISO 11844-1. Corrosion of Metals and Alloys-Classification of Low Corrosivity of Indoor Atmospheres-Part 1: Determina-tion and Estimation of Indoor Corrosivity; International Organization of Standardization: Genève, Switzerland, 2006.

3. Kouřil, M.; Prosek, T.; Scheffel, B.; Dubois, F. High sensitivity electrical resistance sensors for indoor corrosion monitoring. Corros. Eng. Sci. Technol. 2013, 48, 282-287. [CrossRef]

4. Kouril, M.; Prosek, T.; Scheffel, B.; Degres, Y. Corrosion monitoring in archives by the electrical resistance technique. J. Cult. Herit. 2014, 15, 99-103. [CrossRef]

5. Prosek, T.; Taube, M.; Dubois, F.; Thierry, D. Application of automated electrical resistance sensors for measurement of corrosion rate of copper, bronze and iron in model indoor atmospheres containing short-chain volatile carboxylic acids. Corros. Sci. 2014, 87, 376-382. [CrossRef]

6. Ciofi, L.; Zappia, I.; Balleri, R.; Gherardelli, M. RFID applied to the cataloguing of a collection of historical plaster moulds. J. Cult. Herit. 2016, 21, 910-914. [CrossRef]

7. Giuliano, R.; Mazzenga, F.; Petracca, M.; Vatalaro, F. Application of Radio Frequency Identification for Museum Environment. In Enabling Technologies: Infrastructure for Collaborative Enterprises (WETICE) 2013 IEEE 22nd International Workshop; IEEE: Hammamet, Tunisia, 2013; pp. 190-195.

8. Zarifi, M.H.; Deif, S.; Abdolrazzaghi, M.; Chen, B.; Ramsawak, D.; Amyotte, M.; Vahabisani, N.; Hashisho, Z.; Chen, W.; Daneshmand, M. A Microwave Ring Resonator Sensor for Early Detection of Breaches in Pipeline Coatings. IEEE Trans. Ind. Electron. 2018, 65, 1626-1635. [CrossRef]

9. Zarifi, M.H.; Deif, S.; Daneshmand, M. Wireless passive RFID sensor for pipeline integrity monitoring. Sens. Actuators A Phys. 2017, 261, 24-29. [CrossRef]

10. Deif, S.; Daneshmand, M. Long Array of Microwave Sensors for Real-Time Coating Defect Detection. IEEE Trans. Microw. Theory Tech. 2020, 68, 2856-2866. [CrossRef]

11. Deif, S.; Daneshmand, M. Multiresonant Chipless RFID Array System for Coating Defect Detection and Corrosion Prediction. IEEE Trans. Ind. Electron. 2020, 67, 8868-8877. [CrossRef]

12. Khalifeh, R.; Yasri, M.S.; Lescop, B.; Gallee, F.; Diler, E.; Thierry, D.; Rioual, S. Development of Wireless and Passive Corrosion Sensors for Material Degradation Monitoring in Coastal Zones and Immersed Environment. IEEE J. Ocean. Eng. 2016, 41, 776-782. [CrossRef]

13. Yasri, M.; Lescop, B.; Diler, E.; Gallée, F.; Thierry, D.; Rioual, S. Monitoring uniform and localised corrosion by a radiofre-quency sensing method. Sens. Actuators B Chem. 2018, 257, 988-992. [CrossRef]

14. Khalifeh, R.; Lescop, B.; Gallée, F.; Rioual, S. Development of a radio frequency resonator for monitoring water diffusion in organic coatings. Sens. Actuators A Phys. 2016, 247, 30-36. [CrossRef]

15. Sunny, A.I.; Tian, G.Y. Low frequency (LF) RFID sensors and selective transient feature extraction for corrosion characteri-zation. Sens. Actuators A Phys. 2016, 241, 34-43. [CrossRef] 
16. Sunny, A.I.; Zhang, J.; Tian, G.Y.; Tang, C.; Rafique, W.; Zhao, A.; Fan, M. Temperature Independent Defect Monitoring Using Passive Wireless RFID Sensing System. IEEE Sens. J. 2019, 19, 1525-1532. [CrossRef]

17. Zhang, J.; Tian, G.Y. UHF RFID Tag Antenna-Based Sensing for Corrosion Detection \& Characterization Using Principal Component Analysis. IEEE Trans. Antennas Propag. 2016, 64, 4405-4414.

18. Soodmand, S.; Zhao, A.; Tian, G.Y. UHF RFID system for wirelessly detection of corrosion based on resonance frequency shift in forward interrogation power. IET Microw. Antennas Propag. 2018, 12, 1877-1884. [CrossRef]

19. El Masri, I.; Lescop, B.; Talbot, P.; Vien, G.N.; Becker, J.; Thierry, D.; Rioual, S. Development of a RFID sensitive tag dedicated to the monitoring of the environmental corrosiveness for indoor applications. Sens. Actuators B Chem. 2020, 322, 128602. [CrossRef]

20. Bouzaffour, K.; Lescop, B.; Talbot, P.; Gallee, F.; Rioual, S. Development of an embedded UHF-RFID corrosion sensor for monitoring corrosion of steel in concrete. IEEE Sens. J. 2021, 21, 12306-12312. [CrossRef]

21. Hocker, E.; Almkvist, G.; Sahlstedt, M. The Vasa experience with polyethylene glycol: A conservator's perspective. J. Cult. Herit. 2012, 13, S175-S182. [CrossRef]

22. Taglieri, G.; Daniele, V.; Macera, L.; Schweins, R.; Zorzi, S.; Capron, M.; Chaumat, G.; Mondelli, C. Sustainable Nanotech-nologies for Curative and Preventive Wood Deacidification Treatments: An Eco-Friendly and Innovative Approach. Nanomaterials 2020, 10, 1744. [CrossRef] [PubMed]

23. Feng, J.; Tian, H.; Huang, Y.; Ding, Z.; Yin, Z. Pyrite oxidation mechanism in aqueous medium. J. Chin. Chem. Soc. 2019, 66, 345-354. [CrossRef]

24. Chandra, A.; Gerson, A. The mechanisms of pyrite oxidation and leaching: A fundamental perspective. Surf. Sci. Rep. 2010, 65, 293-315. [CrossRef]

25. Jerz, J.K.; Rimstidt, J. Pyrite oxidation in moist air. Geochim. Cosmochim. Acta 2004, 68, 701-714. [CrossRef]

26. Perdicakis, M.; Geoffroy, S.; Grosselin, N.; Bessiere, J. Application of the scanning reference electrode technique to evidence the corrosion of a natural conducting mineral: Pyrite. Inhibiting role of thymol. Electrochim. Acta 2001, 47, 211-216. [CrossRef]

27. Smith, G.D.; Clark, R.J. The role of H2S in pigment blackening. J. Cult. Herit. 2002, 3, 101-105. [CrossRef]

28. Coccato, A.; Moens, L.; Vandenabeele, P. On the stability of mediaeval inorganic pigments: A literature review of the effect of climate, material selection, biological activity, analysis and conservation treatments. Herit. Sci. 2017, 5, 70. [CrossRef]

29. Canosa, E.; Norrehed, S. Strategies for Pollutant Monitoring in Museum Environments. Swedish National Heritage Board 2019. Available online: http:/ /rgdoi.net/10.13140/RG.2.2.24172.00640 (accessed on 29 May 2021).

30. Barclay, R.L.; Dignard, C.; Selwyn, M. Caring for metal objects. Canadian Conservation Institute 2020. Available online: http:/ / www.publications.gc.ca/site/fra/9.888183/publication.html (accessed on 29 May 2021).

31. Sease, C.; Selwyn, L.S.; Zubiate, S.; Bowers, D.F.; Atkins, D.R. Problems with coated silver: Whisker formation and possible filiform corrosion. Stud. Conserv. 1997, 42, 1-10.

32. Ehsan, M.A.; Khaledi, H.; Tahir, A.A.; Ming, H.N.; Wijayantha, K.U.; Mazhar, M. Synthesis and characterization of silver diethyldithiocarbamate cluster for the deposition of acanthite (Ag2S) thin films for photoelectrochemical applications. Thin Solid Films 2013, 536, 124-129. [CrossRef]

33. Volpe, L.; Peterson, P.J. ChemInform Abstract: The Atmospheric Sulfidation of Silver in a Tubular Corrosion Reactor. Corros. Sci. 1989, 29, 1189-1196. [CrossRef]

34. Pope, D.; Gibbens, H.; Moss, R. The tarnishing of Ag at naturally-occurring $\mathrm{H}_{2} \mathrm{~S}$ and $\mathrm{SO}_{2}$ levels. Corros. Sci. 1968, 8, 883-887. [CrossRef]

35. Franey, J.; Kammlott, G.; Graedel, T.E. The corrosion of silver by atmospheric sulfurous gases. Corros. Sci. 1985, 25, 133-143. [CrossRef]

36. Bauer, R. Sulfide corrosion of silver contacts during satellite storage. J. Spacecr. Rocket. 1988, 25, 439-440. [CrossRef]

37. Conyers, J.L., Jr.; White, H.S. Electrochemical growth of $\mathrm{Ag}_{2} \mathrm{~S}$ on $\mathrm{Ag}(111)$ electrodes. Coulometric and X-ray photoelectron spectroscopic analysis of the stepwise formation of the first and second monolayers of $\mathrm{Ag}_{2}$ S. J. Phys. Chem. B 1999, 103, $1960-1965$. [CrossRef]

38. Hart, L.T.; Storme, P.; Anaf, W.; Nuyts, G.; Vanmeert, F.; Dorriné, W.; Janssens, K.; de Wael, K.; Schalm, O. Monitoring the impact of the indoor air quality on silver cultural heritage objects using passive and continuous corrosion rate assessments. Appl. Phys. A 2016, 122, 923. [CrossRef] 